\title{
Electrophysiological estimates of biological and syntactic gender access during pronoun processing.
}

Citation for published version (APA):

Schmitt, B. M., Lamers, M., \& Münte, T. F. (2002). Electrophysiological estimates of biological and syntactic gender access during pronoun processing. Cognitive Brain Research, 14, 333-46. https://doi.org/10.1016/S0926-6410(02)00136-2

Document status and date:

Published: 01/01/2002

DOI:

10.1016/S0926-6410(02)00136-2

Document Version:

Publisher's PDF, also known as Version of record

Document license:

Taverne

Please check the document version of this publication:

- A submitted manuscript is the version of the article upon submission and before peer-review. There can be important differences between the submitted version and the official published version of record.

People interested in the research are advised to contact the author for the final version of the publication, or visit the DOI to the publisher's website.

- The final author version and the galley proof are versions of the publication after peer review.

- The final published version features the final layout of the paper including the volume, issue and page numbers.

Link to publication

\footnotetext{
General rights rights.

- You may freely distribute the URL identifying the publication in the public portal. please follow below link for the End User Agreement:

www.umlib.nl/taverne-license

Take down policy

If you believe that this document breaches copyright please contact us at:

repository@maastrichtuniversity.nl

providing details and we will investigate your claim.
}

Copyright and moral rights for the publications made accessible in the public portal are retained by the authors and/or other copyright owners and it is a condition of accessing publications that users recognise and abide by the legal requirements associated with these

- Users may download and print one copy of any publication from the public portal for the purpose of private study or research.

- You may not further distribute the material or use it for any profit-making activity or commercial gain

If the publication is distributed under the terms of Article $25 \mathrm{fa}$ of the Dutch Copyright Act, indicated by the "Taverne" license above, 


\title{
Electrophysiological estimates of biological and syntactic gender violation during pronoun processing
}

\author{
Bernadette M. Schmitt ${ }^{\mathrm{a}, *}$, Monique Lamers ${ }^{\mathrm{a}, \mathrm{b}}$, Thomas F. Münte ${ }^{\mathrm{b}}$ \\ ${ }^{a}$ Department of Neurocognition, Faculty of Psychology, Maastricht University, PO Box 616, 6200 MD Maastricht, The Netherlands \\ ${ }^{\mathrm{b}}$ Department of Neuropsychology, Otto-von-Guericke-Universität Magdeburg, Magdeburg, Germany
}

Accepted 5 March 2002

\begin{abstract}
During comprehension, a personal pronoun (he, she, it) refers to a preceding referent (boy, girl, child). This co-reference could be established, among other ways, by using (i) conceptual/semantic information (biological gender agreement between the pronoun and its referent), (ii) syntactic information (syntactic gender agreement), or (iii) both. This event-related brain potential (ERP) study assesses this interplay of syntactic and semantic information. We focussed on the N400 component, related to semantic integration, and the SPS/P600 component, related to syntactic reanalysis. The study was conducted in German, because its rich syntactic gender system offers a means to dissociate between biological (MALE/FEMALE) and syntactic gender (masculine/feminine/neuter), especially in the case of diminutives $\left(\right.$ das $_{\text {neuter }}$ Bübchen $_{\text {MALE }}$ [the little boy]). German subjects read sentences in which a referent $\left(\right.$ Bübchen $_{\text {MALE-neuter }} /$ Bub $_{\text {MALE-masculine }}$ [boy]) was introduced. Later a personal pronoun was presented which either agreed with the referent in terms of syntactic gender, or in terms of biological gender, or both, or violated both agreements. Overall, results showed salient P600 effects for pronouns. This indicates that the establishment of reference involves syntactic reanalysis. Furthermore, we observed N400 effects in sentences with nondiminutives, but not with diminutives. This shows that conceptual/semantic integration is involved during non-diminutive but not during diminutive pronoun processing, or at least it could not be violated. The overall pattern of results supports the claim that for non-diminutives, both syntactic and conceptual information is used to establish co-reference, while for diminutives the process might be purely syntactically driven.
\end{abstract}

(C) 2002 Elsevier Science B.V. All rights reserved.

Theme: Neural basis of behaviour

Topic: Cognition

Keywords: Language; Pronoun processing; Meaning and syntax; Gender access; N400; P600

\section{Introduction}

We use language to refer to things or events. Once something has been mentioned in discourse, it can be re-referred to via certain linguistic devices. These devices are sometimes called anaphors, and the events or things they refer to are called antecedents or referents. Such a device can be a reduced form, as the personal pronoun 'she' that refers to the little girl in the sentence 'The little girl was in a good mood and therefore she smiled a lot'. But how does the comprehender know this, i.e how does

\footnotetext{
*Corresponding author. Tel.: +31-43-388-1934; fax: +31-43-3884125 .

E-mail address: b.schmitt@psychology.unimaas.nl (B.M. Schmitt).
}

the comprehension system establishes co-reference? This question has interested generative linguists, artificial intelligence specialists, and psycholinguists for quite some time; for a review see Ref. [7]. There is still ongoing debate about what kind of information is accessed during pronoun comprehension. Some psycholinguistic studies have shown that conceptual/semantic information is relevant [6], while others showed involvement of syntactic information [4,7], or both [4]. In addition, there is an ongoing debate about how this information is used to connect a pronoun and a reference. In general, a two-step process is assumed. First, the readers/listener initially loosely connects a pronoun to a possible antecedent, a process referred to as bonding or co-indexing. Second, this initial link is then established, which is referred to as 
integration or resolution (see Ref. [5] for a recent discussion on bonding and resolution). The aim of this study is to use an electrophysiological approach to find out more details about the kind of information that is involved in pronoun comprehension. We will use an ERP violation paradigm to investigate this question. However, because until now it has not been known whether a violation interferes with the process of bonding and/or integration, this study will not comment on bonding versus integration, but will focus on the type of information. When we use the term 'establish co-reference' we refer to the process as a whole without separating bonding and integration.

Event related potentials (ERP), due to their high temporal resolution, are suited to investigate the temporal aspects of information processing, as well as the kind of information processed during pronoun comprehension. The ERP is an electrophysiological measure of brain activity during the processing of cognitive tasks [18,24] (for language see Refs. [13,23]). The so-called N400 component has been shown to be sensitive to semantic integration [12,14], as well as to discourse integration $[25,26]$. The P600/SPS (syntactic positive shift) has been interpreted as being sensitive to syntactic processing $[9,19]$ (for a review see Ref. [10]), or reanalysis of the sentence $[16,17]$. This means that for the interpretation of both components there is a tendency to see them reflecting integration/reanalysis. However, whether or not they might reflect integration and/or bonding during pronoun comprehension is unknown, and we therefore will not separate these two processes here. Previous ERP research by others on pronoun comprehension focused either on syntactic or semantic violation. The present study is the first to investigate the interaction of the two types of information.

\subsection{Evidence for syntactic co-reference}

Osterhout and Mobley [20] studied the processing of number and gender agreement violations in a sentence. In their view, if a violation was semantic it should give rise to an $\mathrm{N} 400$, whereas a syntactic violation should be reflected in a P600. A sentence such as 'The boy next door never loses her temper with anyone' would be judged as not acceptable by most readers. One could claim that the sentence is grammatically incorrect because the syntactic gender of the pronoun does not agree with the syntactic gender of the antecedents. Alternatively, one could argue that the violation is conceptual/semantic. Part of the meaning of 'boy' denotes male and human, whereas the meaning of the pronoun 'her' refers to something female and human. Among other sentence types, Osterhout and Mobley presented two types of violations: (i) 'The hungry guests helped themselves/himself to the food' (reflexiveantecedent number agreement); and (ii) 'The successful woman congratulated herself/himself on the promotion' (reflexive-antecedent gender agreement). Participants were asked to read the sentences and to make a sentenceacceptability judgement afterwards. The results showed a P600 for both types of sentences. As no N400 like component was observed, semantic (violation) integration was deemed to be of no or minor importance. This ERP experiment supported the interpretation that pronouns use syntactic constraints to establish co-reference but no semantic integration, because it could not be violated. Similar effects were observed for German case marked relative pronouns in a reading study by Friederici et al. [3].

\subsection{Evidence for conceptual and discourse co-reference}

The question has been addressed as to whether pronouns can also access processing levels other than the syntactic level. King and Kutas [11] (see also Ref. [13]) examined how a conceptual cue, the probable biological gender of a referent, affected the establishment of anaphoric co-reference. By means of a rating test, the authors derived probabilities that a worker in a specific job was expected to be male or female. The results of the rating showed that stereotypes exist. For example, an engineer was rated as being rather male. In contrast, a secretary was expected to be rather female. King and Kutas then presented sentences in which personal pronouns matched or mismatched the stereotype, as in 'The engineer designed the machine because he/she...'. The authors observed two salient patterns in the ERP data. First, the pronouns in the mismatching condition elicited a larger negativity at left anterior sites than the pronouns in the matching condition. This negativity was evident by $200 \mathrm{~ms}$ post onset and according to the authors might be related to working memory and/or discourse integration. Alternatively, the observed effect could be a left anterior negativity (LAN) related to syntactic analysis: 'the engineer' was analysed syntactically as masculine, and at the moment the mismatching pronoun 'she' is presented the system discovers a syntactic mismatch. The second finding was that mismatching pronouns elicited a larger N400 component. Thus, the integration of the pronouns into the sentence, i.e. the establishment of co-reference, might involve semantic and discourse processing of words. In a related study by Osterhout and colleagues [22] reflexive pronouns that mismatched the gender of stereotypes elicited a P600/SPS like component, and no N400. Thus, ERP results vary between studies, and it is still not entirely clear what sort of information is actually accessed during pronoun processing.

The aim of this study is to investigate the type of information used during pronoun comprehension. We focused on the agreement of conceptual/semantic and/or syntactic gender between referent and pronoun, and its violation in German. German was used, because its rich syntactic gender system offers a means to dissociate biological gender (MALE/FEMALE) and syntactic gender (masculine/feminine/neuter), especially in the case of 


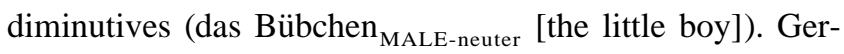
man subjects read sentences in which a referent (Bübchen MALE-neuter [little boy]/Bub mALE-masculine [boy]) was introduced in the first noun phrase. In a second noun phrase a personal pronoun was presented. Please see Table 1 for examples of sentences from all conditions and their labels used throughout the text and in the figures. The D refers to diminutive, $\mathrm{N}$ refers to non-diminutives, $\mathrm{S}$ is syntactic gender, B is biological gender, - is violation, and + is agreement. As can be seen in the table, the pronoun either agreed with the referent in terms of biological gender ('er' [he masculine $]$ for 'Bübchen'; condition $\mathrm{D} / \mathrm{B}+\mathrm{S}-$ ), in terms of syntactic gender ('es' [it neuter ] for 'Bübchen'; condition $\mathrm{D} / \mathrm{B}-\mathrm{S}+$ ), disagreed in both ('sie' [ $\mathrm{she}_{\text {feminine }}$ ]; condition $\mathrm{D} / \mathrm{B}-\mathrm{S}-$ ), or agreed in both syntactic and biological gender ('er' [he] for 'Bub'; condition $\mathrm{N} / \mathrm{B}+\mathrm{S}+$ ). There are two further double violation conditions $(\mathrm{N} / \mathrm{B} * \mathrm{~S} * \mathrm{~N} /$ $\mathrm{B}-\mathrm{S}-$ ). We label them differently to differentiate between

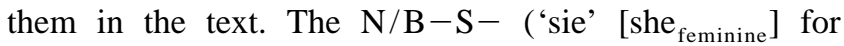
'Bub') is a transparent double violation using incorrect biological gender, which also is incorrect syntactic gender. The $\mathrm{N} / \mathrm{B}^{*} \mathrm{~S}^{*}$ is a double violation as well. The pronoun 'es' [it neuter $]$ disagreed in biological and syntactic gender with the referent 'Bub'. But, this double violation might be slightly different from the $\mathrm{N} / \mathrm{B}-\mathrm{S}-$ in the sense that instead of an explicitly incorrect biological gender no biological gender is used. We did not know beforehand whether and how these two conditions might differ in the ERP signal.

Frequency counts of pronoun usage (production) based on a corpus of written German revealed that in $63 \%$ of all diminutive referent cases a pronoun is selected that agreed in biological gender ( $\mathrm{D} / \mathrm{B}+\mathrm{S}-$ condition). Only in $37 \%$ is

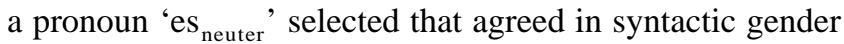
with the diminutive referent ( $\mathrm{D} / \mathrm{B}-\mathrm{S}+$ condition) (Cosmas database [1]). This means that the violation conditions in all diminutive cases are acceptable, with somewhat different probabilistic weights: $\mathrm{D} / \mathrm{B}+\mathrm{S}-$ has a 0.63 chance of being acceptable while $\mathrm{D} / \mathrm{B}-\mathrm{S}+$ has a 0.37 chance of being acceptable. The third diminutive condition $\mathrm{D} / \mathrm{B}-\mathrm{S}-$ is not acceptable, as are the non-diminutive conditions $\mathrm{N} / \mathrm{B} * \mathrm{~S} *$ and $\mathrm{N} / \mathrm{B}-\mathrm{S}-$. We therefore see the non-diminutives condition $\mathrm{N} / \mathrm{B}+\mathrm{S}+$ as a baseline, because it is the only condition that can be seen as $100 \%$ acceptable in this experiment, and we see the violations as 'probabilistic' violations. We assume that if the production system accepts two types of constructions $(\mathrm{D} / \mathrm{B}+\mathrm{S}-$ and $\mathrm{D} / \mathrm{B}-\mathrm{S}+$ ) the comprehension system would do so, too.

While subjects read these sentences, their event-related brain potentials (ERP) were recorded. Following the logic of other N400/P600 ERP research, we propose the following hypothesis: If biological gender information is involved during pronoun comprehension (either in terms of bonding or in terms of integration), and this conceptual/ semantic information is violated (as in the German 'es' pronoun case, $\mathrm{D} / \mathrm{B}-\mathrm{S}+$ ), an $\mathrm{N} 400$ effect should be visible in biological gender violations as compared to cases with no such violation. If syntactic gender information is involved (either in terms of bonding or integration), we expect a P600 for incorrect syntactic gender agreement compared to syntactically correct sentences (as in D/B+ $\mathrm{S}-$ ). If both conceptual/semantic and syntactic information are relevant, a modulation of the N400/P600 complex for the cases of double violations (as in N/B-S-) should be observed. However, if just one of the types of information is relevant (either biological or syntactic gender), one might expect either an N400 or a P600 in the double violations, respectively. In general, the presentation of the isolated sentences should trigger the comprehension system to interpret the pronoun as belonging to the first noun in the first noun phrase. We have at least two reasons for this assumption. First, as has been shown by others in reading experiments [7], this interpretation seems to be preferred. Second, in isolated sentences there is a lack of alternative referents and, therefore, the pronoun is not 'free' but can only be related to one candidate. Any violation indeed should violate this interpretation process. Besides the discussed conceptual and syntactic based reference, the default reference process might be a discourse driven link between pronoun and referent (probably based on saliency of the candidate in the discourse). In this case we would expect N400 effects in all types of

Table 1

Example materials for the experiment

Condition Sentence

Diminutive as referent

1. $\mathrm{D} / \mathrm{B}+\mathrm{S}-$

2. $\mathrm{D} / \mathrm{B}-\mathrm{S}+$

3. $\mathrm{D} / \mathrm{B}-\mathrm{S}-$

Non-diminutive as referent

4. $\mathrm{N} / \mathrm{B}+\mathrm{S}+$

5. $\mathrm{N} / \mathrm{B} * \mathrm{~S} *$

6. $\mathrm{N} / \mathrm{B}-\mathrm{S}-$

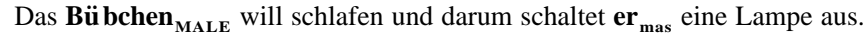
Das Bübchen MALE will schlafen und darum schaltet $\mathbf{e s}_{\text {neu }}$ eine Lampe aus. Das Bübchen $_{\text {MALE }}$ will schlafen und darum schaltet sie $_{\mathbf{f e m}}$ eine Lampe aus.

Der Bub MALE will schlafen und darum schaltet $\mathbf{e r}_{\text {mas }}$ eine Lampe aus. Der Bub MALE $_{\text {ill schlafen und darum schaltet es }}$ weu eine Lampe aus.

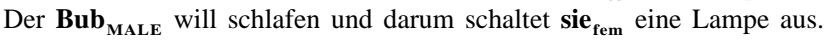

Translation: The (little) boy wants to sleep and therefore he/she/it switches a light off. B, biological gender; D, diminutive; N, non-diminutive; S, syntactic gender, + , agreement, - and *, disagreement between pronoun and antecedent. MALE, biological gender; fem, feminine; mas, syntactic gender masculine; neu, neuter. 
violations compared to the control condition (as has been shown by van Berkum et al. [26]).

\section{Methods}

\subsection{Subjects}

A total of 30 native speakers of German (26 women, mean age 23 years) were recruited from the student population of the Otto-von-Guericke University, Magdeburg, Germany, and were paid for their participation. All had normal or corrected-to-normal vision, were right-handed and neurologically healthy.

\subsection{Material}

A total of 60 nouns specifying persons' professions, titles or states were selected. Half of these nouns represented clearly male or female persons. These nouns were embedded in sentences consisting of a main clause and a subordinate clause, with the noun as the subject of the main clause. The subject (noun) formed the antecedent of the pronoun, which was the subject of the subordinate clause (see Table 1 for an example). Care was taken that in the subordinate clause only verbs were used that do not allow a general 'es' pronoun which might be related to a more general concept in German. For example, in 'und darum regnet es so stark' (and therefore it is raining so heavily), 'es' would not refer to the antecedent at all and one would not measure any sort of violation at that time during sentence processing. We thus excluded these cases. The used sentences, presented in isolation and using the syntactic construction as just described, minimized ambiguity for co-reference.

For each non-diminutive three different sentence contexts were created for later balancing with the three pronoun types (he, she, it) to minimize repetition within participants. All sentences were then copied and the nondiminutive was replaced by a diminutive. The material was distributed across three different lists, counterbalancing the order referent types, pronoun types, repetition, and sentence context. On a given list, a non-diminutive was presented three times in three different contexts and with three different pronouns. The same held for diminutives, resulting in six main conditions as listed in Table 1. Sentences on a list were pseudo-randomized over six blocks in such a way that each condition appeared ten times in each block and repetitions of referents (three times, one for each pronoun) and contexts (two times, one for diminutives, one for non-diminutives) were kept as far a part as possible. Each participant got to read one list, i.e. 60 sentences per condition. We measured ten subjects per list. They were pooled again later for analysis.

A total of 60 filler sentences were added to each block. The filler sentences were the same over the lists. The filler sentences were included in order to avoid the development of expectancies of sentence continuations. In order to keep participants attentive, comprehension questions were presented after 12 sentences (ten experimental sentences and two filler sentences) in each block. Subjects had to push one of two buttons to answer 'yes' or 'no' to a question related to the preceding sentence content. This task was independent of the pronoun manipulation to avoid interference of the explicit comprehension task with the implicit ERP measures of the pronoun manipulations.

The words were presented in 16-point font size at viewing distance of $110 \mathrm{~cm}$. The experimental sentences were equated on word number (ranging from ten to 14 words).

\subsection{Procedure}

Subjects were tested individually in a dimly lit soundattenuating booth. They were seated in a comfortable chair. They were instructed to read the sentences carefully, because they would be asked from time to time to answer questions related to the content of the sentences. They were free to blink and move their eyes between sentences and while answering questions, but should fixate on the screen and avoid all movement during the word-by-word presentation of the sentences.

Each trial began with the presentation of a fixation cross in the middle of the screen, followed by a $350-\mathrm{ms}$ presentation of the word, a 300-ms inter-stimulus interval, and the presentation of the next word. Sentence ending words were presented with a 'dot' to indicate the end of the sentence, followed by a blank screen for $850 \mathrm{~ms}$. Questions were presented for $5 \mathrm{~s}$. After each block the subjects received feedback on their performance on the questions. In the middle of each block there was a pause of $30 \mathrm{~s}$, followed by a filler sentence to warn the subject to be prepared for the second part of that block. Each block lasted $\sim 20 \mathrm{~min}$. The entire experiment, including electrode application and removal took $2.5 \mathrm{~h}$.

\subsection{EEG recording and analysis}

ERPs were recorded from the scalp using 28 tin electrodes mounted in an elastic cap. Electrode-sites according to the 10/20 system were: Fp1/2, F7/8, F3/4, C3/4, T3/4, Fz, Cz, Pz, Fc1/2, Cp1/2, Po1/Po2, P3/4, T5/6, To1/To2, O1/2, Oz. Bio-signals were recorded with a left mastoid reference, and were re-referenced off-line to the mean of the activity at the two mastoid processes. Blinks and vertical eye movements were monitored with electrodes placed at the sub- and supraorbital ridge of the left eye. Lateral eye movements were monitored by a bipolar montage using two electrodes placed on the right and left external canthus. Eye movements were recorded in order to allow for later offline rejection, which was carried out by a computer program based on individualized 
rejection criteria. All electrode impedances (EEG and EOG) were kept below $5 \mathrm{k} \Omega$.

Electrophysiological signals were amplified with a bandpass filter of $0.01-50 \mathrm{~Hz}$ and digitised at a rate of $250 \mathrm{~Hz}$ (4-ms resolution). From the continuous signal epochs were created of $1024 \mathrm{~ms}$ starting $100 \mathrm{~ms}$ prior to pronoun onset. The signal was monitored for artefacts, such as eyemovements. Trials including artefacts were rejected based on individual rejection criteria (30\% rejections on average, no difference across conditions). Averages were computed across all remaining trials per condition. Subsequent ANOVAs used mean amplitude values (relative to the 100-ms pre-stimulus baseline) computed for each subject and each condition. The N400 mean amplitude values were taken from a latency window of 320-380 ms after pronoun onset. This window has been defined by visual inspection of the effect in the grand average ERP signal. Note that this window diverges from a standard N400 time window (usually between 300 and $500 \mathrm{~ms}$ ) in order to avoid overlap with the P600 time window. The P600 mean amplitude values were analysed for a standard P600 time window of 400-700 ms after onset of the pronoun.

Univariate $F$-tests with more than $1 \mathrm{df}$ in the numerator were adjusted by means of the Greenhouse-Geisser correction. All results were first evaluated in an omnibus ANOVA that crossed the factors 'electrode sites' (28) with pronoun type (three: er, sie, es) and referent type (two: non-diminutives and diminutives). The scalp distributions of the N400 and P600 effects were subsequently explored in two separate ANOVAs, one with a hemisphere (left, right) by lateral-electrodes (12 left, 12 right of midline sites) design, and one with a front-to-back by electrodes (nine anterior electrodes, nine posterior electrodes) design. Planned pair-wise comparisons between conditions were carried out per electrode site in case of significant main effects or interactions. Note that due to interaction of referent type and pronoun types in the material, the six conditions all involve slightly different aspects of language processing and violations, as labelled in Table 1. We therefore consider planned pair-wise comparison as the most informative statistic. We were interested in a comparison of conditions that either varied in syntactic or conceptual gender agreement, or in both, looking at N400 and P600 time windows separately.

\section{Results}

The grand average ERPs, time-locked to the onset of the critical pronoun, are shown in Figs. 1 and 2. Fig. 1 shows the ERP wave for the three pronoun types when the referent was a diminutive. Fig. 2 shows the ERPs of the

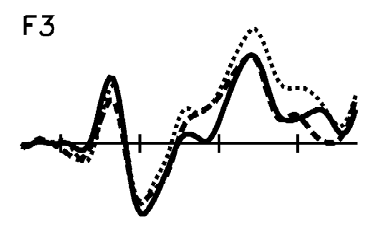

$\mathrm{Fz}$

F4

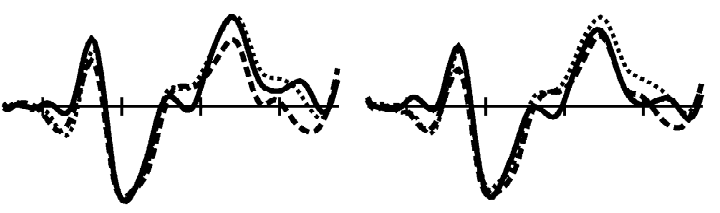

C3

$\mathrm{Cz}$

C4

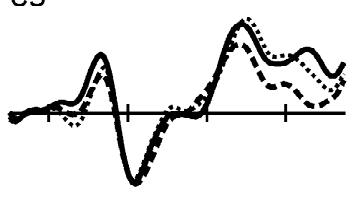

P3

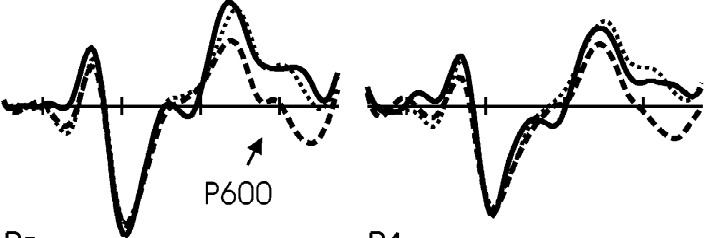

P4
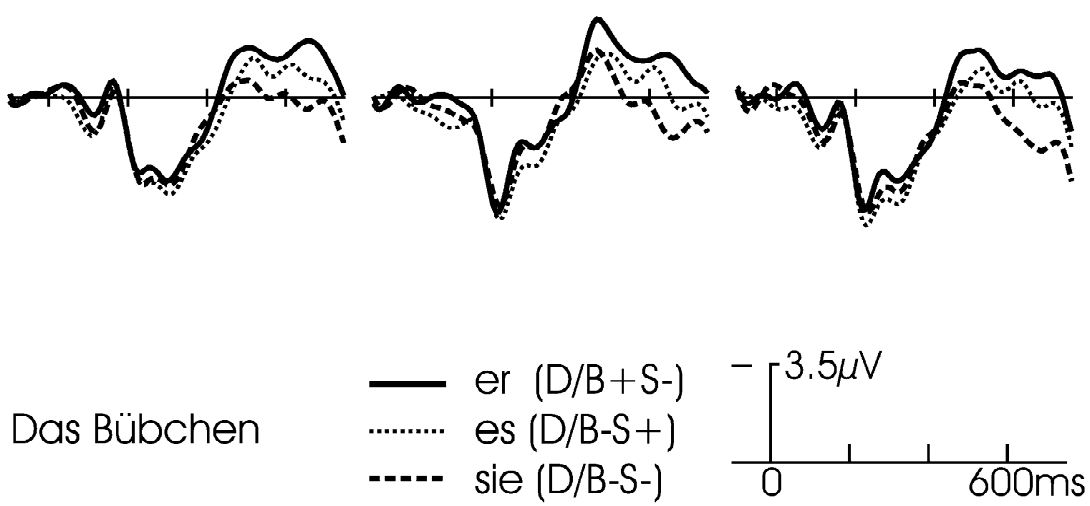

Fig. 1. Grand average ERPs $(n=30)$ time locked to the onset of the critical pronoun in sentences with diminutives as referent at the nine most central electrode sites. Negative voltage is plotted up; c, central; f, frontal; p, parietal; $\mathrm{z}$, midline, in this and all subsequent figures. Conditions and their labels are illustrated in Table 1. 

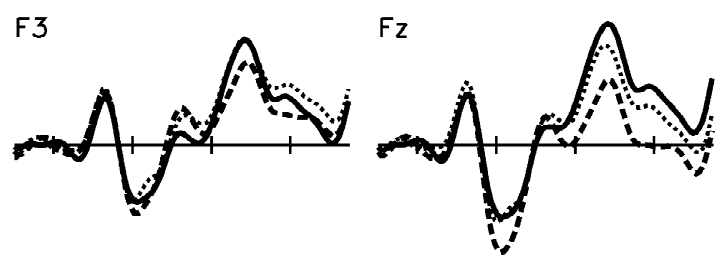

F4

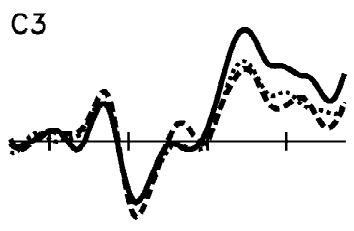

P3

$\mathrm{Cz}$

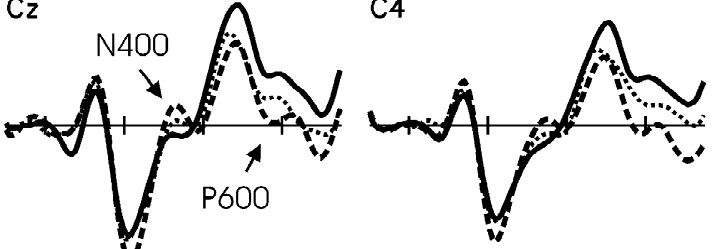

P4

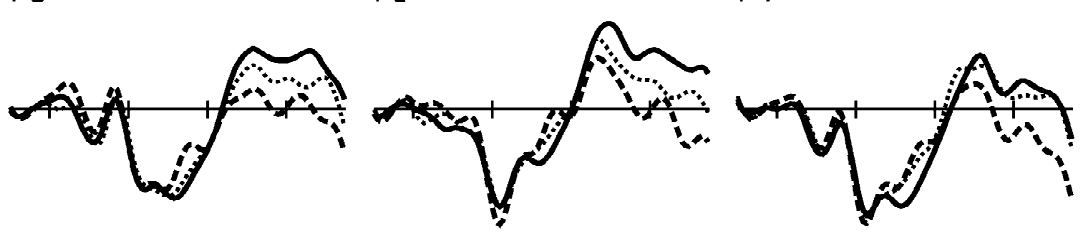

Der Bub

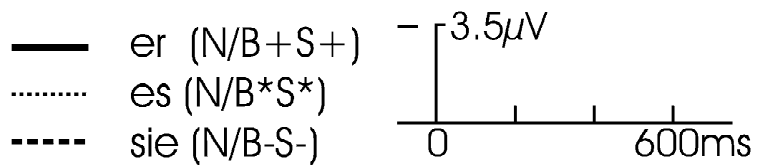

Fig. 2. Grand average ERPs $(n=30)$ time locked to the onset of the critical pronoun in sentences with non-diminutives as referent at the nine most central electrode sites. Conditions and their labels are illustrated in Table 1.

three pronoun types when the referent was a non-diminutive.

All six conditions elicit a N1-P2 complex that is typical for visually presented material, as well as a P1 component at occipital sites. Around $300 \mathrm{~ms}$ post stimulus, all pronoun types elicit a clear negative deflection. In the 320-380-ms time window this deflection is different between pronoun types when a non-diminutive was a referent (Fig. 2), suggesting a modulation of the N400 component. This N400 pattern is not visible when a diminutive was the referent (Fig. 1). In a later time window (400-700 ms), the deflection shows differences independent of the type of the referent. It is more positive for violations as compared to non-violations, especially at central and parietal sites, indicating P600 effects. It is also more positive for double violations as compared to single violations.

Statistical analysis is reported separately for the N400 and P600 latency range. Omnibus, hemispheric and anterior-posterior ANOVAs are reported in Table 2 for the N400 range and in Table 3 for the P600 range. Pair-wise comparisons are displayed together with mean amplitude measures of the critical intervals in Fig. 3 for the N400 latency range, and in Fig. 4 for the P600 latency range. Solid lines between pairs indicate significant differences (all $P<0.05$ ).

\section{1. $N 400$}

Table 2 revealed that our pronoun manipulation in an omnibus ANOVA did not show significant main effects, but a significant pronoun type $\times$ referent type $\times$ electrode interaction. This indicates that the effect is not widespread over the entire scalp, but is present only at specific sites. Specific topographical analyses showed that the N400 effect was not different between hemispheres (non-significant pronoun type $\times$ hemisphere interaction), but that it was significantly larger over posterior sites (significant pronoun type $\times$ ant-pos interaction).

Fig. 3 shows mean amplitudes per condition per electrode site. Note that the labels at the $x$-axis in Fig. 3 relate to the conditions in Table 1. As can be seen in the figure, mean amplitude values were different between conditions, being most salient at parietal sites. For example, there is a salient decrease of positive amplitudes from condition $\mathrm{N} / \mathrm{B}+\mathrm{S}+$ to $\mathrm{N} / \mathrm{B} * \mathrm{~S} *$ to $\mathrm{N} / \mathrm{B}-\mathrm{S}-$, i.e. an increase of the $\mathrm{N} 400$ component in pronoun processing in non-diminutive sentences. No such clear change in mean amplitudes is visible between the diminutive conditions, indicating no salient N400 effect for pronoun processing in diminutive sentences.

Planned pair-wise comparisons between conditions were carried out separately for each of the nine most central 
Table 2

Biological gender agreement effects: mean ERP amplitude ANOVAs in the 320-380-ms latency range (N400)

\begin{tabular}{|c|c|c|c|}
\hline Source & df & $F$ & $P(\mathrm{GG})$ \\
\hline \multicolumn{4}{|l|}{ Omnibus ANOVA (28 electrodes) } \\
\hline Pronoun (er, sie, es) $\times$ el & 54,1566 & 2.03 & 0.053 \\
\hline Referent (non-dim., diminutive) $\times \mathrm{el}$ & & & NS \\
\hline Pronoun $\times$ referent $\times$ el & 54,1566 & 2.96 & $0.004 * *$ \\
\hline \multicolumn{4}{|l|}{ Lateral ANOVA $(2 \times 12$ electrodes $)$} \\
\hline Pronoun $\times \mathrm{el}$ & 22, 638 & 2.46 & $0.04 *$ \\
\hline Pronoun $\times$ referent $\times$ el & 22, 638 & 3.64 & $0.004 * *$ \\
\hline Pronoun $\times$ referent $\times$ he & 2,58 & 3.62 & $0.03^{*}$ \\
\hline Pronoun $\times$ referent $\times$ el $\times$ he & 22,638 & 1.87 & $0.009 * *$ \\
\hline \multicolumn{4}{|c|}{ Anterior-posterior ANOVA ( $2 \times 9$ electrodes $)$} \\
\hline Pronoun $\times$ ant - pos & 2,58 & 3.47 & $0.04 *$ \\
\hline Pronoun $\times$ NP $\times$ ant - pos & 2,58 & 6.18 & $0.004 * *$ \\
\hline Pronoun $\times$ el $\times$ ant-pos & 16,464 & 2.92 & $0.03^{*}$ \\
\hline Pronoun $\times$ referent $\times$ el $\times$ ant-pos & 16,464 & 1.97 & 0.07 \\
\hline
\end{tabular}

Pairwise comparison for nine sites as shown in Fig. 3. Solid lines between pairs indicate significant difference $(P<0.05)$. Ant-pos, anterior-posterior; el, electrode; he, hemisphere. Table only displays ANOVA tests that are most relevant. All effects that are not reported are not significant (NS).

$* P<0.05 ; * * P<0.01$ (GG, Greenhouse Geisser corrected $P$-value for $F$-tests with more than $1 \mathrm{df}$ ).

sites (Fz, Cz, Pz, F3/4, C3/4, P3/4). The significant differences between conditions are shown as solid lines between pairs in Fig. 3 (all $P<0.05$ ).

\subsubsection{Diminutives as referent}

All planned comparisons between the different diminutive conditions failed to reveal a difference. This result indicates that there are no processing differences in the three sentence types in the N400 time window.

\subsubsection{Non-diminutives as referent}

The comparisons between N/B+S + and N/B-S(double agreement vs. double violation) were significant at all parietal sites, indicating N400 effects. The comparison between $\mathrm{N} / \mathrm{B}+\mathrm{S}+$ and $\mathrm{N} / \mathrm{B} * \mathrm{~S} *$ was not significant. The comparison between N/B* $\mathrm{S}^{*}$ and N/B-S- was significant at left parietal site P3. These results showed that there is a salient processing difference between baseline sentence type $(\mathrm{N} / \mathrm{B}+\mathrm{S}+)$ and sentences with clear biological gender violation $(\mathrm{N} / \mathrm{B}-\mathrm{S}-$ ) in the $\mathrm{N} 400$ time window.

Table 3

Syntactic gender agreement effects: mean ERP amplitude ANOVAs in the 400-700-ms latency range (P600)

\begin{tabular}{|c|c|c|c|}
\hline Source & $\mathrm{df}$ & $F$ & $P(\mathrm{GG})$ \\
\hline \multicolumn{4}{|l|}{ Omnibus ANOVA (28 electrodes) } \\
\hline Pronoun (er, sie, es) & 2,58 & 6.95 & $0.002 * *$ \\
\hline Referent (non-dim., diminutive) & & & NS \\
\hline Pronoun $\times \mathrm{el}$ & 54,1566 & 2.52 & $0.012^{*}$ \\
\hline Referent $\times \mathrm{el}$ & & & NS \\
\hline Pronoun $\times$ referent $\times$ el & 54,1566 & 2.12 & $0.035^{*}$ \\
\hline \multicolumn{4}{|l|}{ Lateral ANOVA $(2 \times 12$ electrodes $)$} \\
\hline Pronoun (er, sie, es) & 2,58 & 6.48 & $0.003^{* *}$ \\
\hline Referent (non-dim., diminutive) & & & NS \\
\hline Pronoun $\times$ el & 22,638 & 3.12 & $0.010^{*}$ \\
\hline Pronoun $\times \mathrm{el} \times$ he & & & NS \\
\hline Pronoun $\times$ referent $\times$ el $\times$ he & & & NS \\
\hline \multicolumn{4}{|c|}{ Anterior-posterior ANOVA ( $2 \times 9$ electrodes $)$} \\
\hline Pronoun (er, sie, es) & 2,58 & 6.46 & $0.003^{* *}$ \\
\hline Referent (non-dim., diminutive) & & & NS \\
\hline Pronoun $\times$ el & 16,464 & 2.16 & $0.007 * *$ \\
\hline Pronoun $\times$ el $\times$ ant - pos & & & NS \\
\hline Pronoun $\times$ referent $\times$ el & 16,464 & 2.62 & $0.013^{*}$ \\
\hline Pronoun $\times$ referent $\times$ el $\times$ ant-pos & & & NS \\
\hline
\end{tabular}

Pairwise comparison for nine sites as shown in Fig. 4. Solid lines between pairs indicate significant difference $(P<0.05)$. Ant-pos, anterior-posterior; el, electrode; he, hemisphere. Table only displays ANOVA tests that are most relevant. All effects that are not reported are not significant (NS).

$* P<0.05 ; * * P<0.01$ (GG, Greenhouse Geisser corrected $P$-value for $F$-tests with more than $1 \mathrm{df}$ ). 
F3

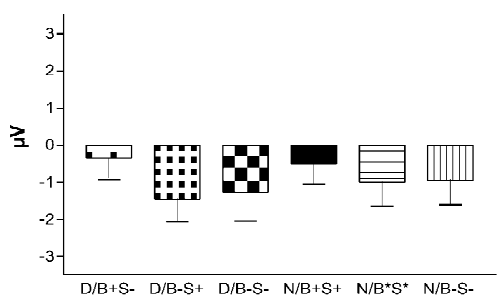

C3

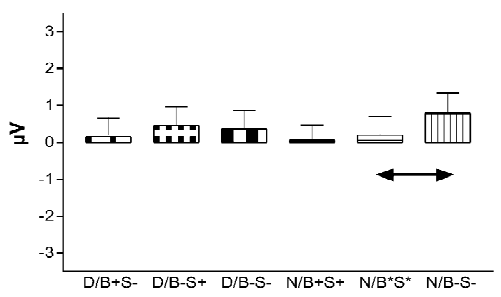

P3

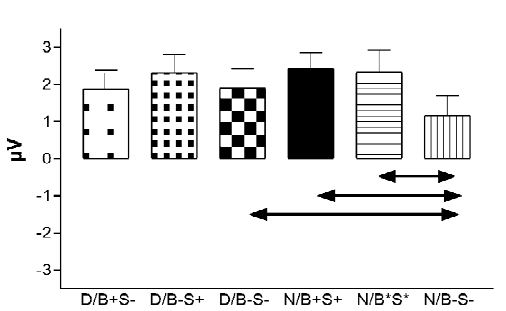

$\mathbf{F z}$

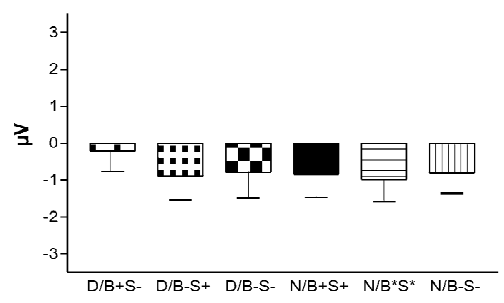

$\mathrm{Cz}$

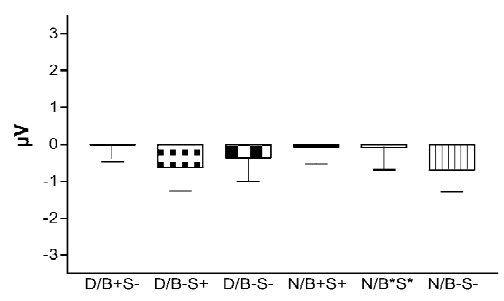

Pz

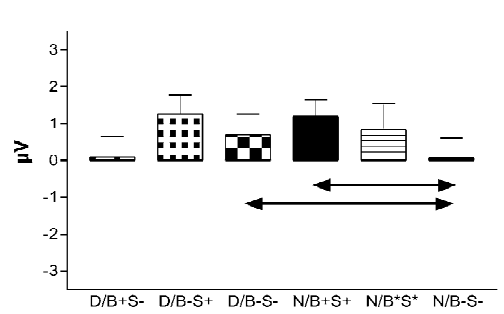

F4

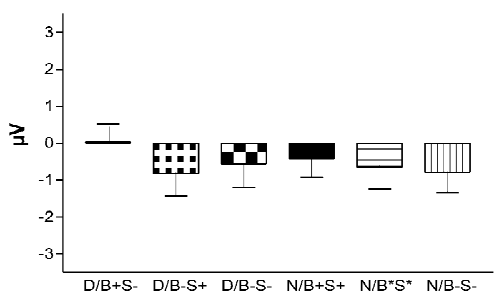

C4

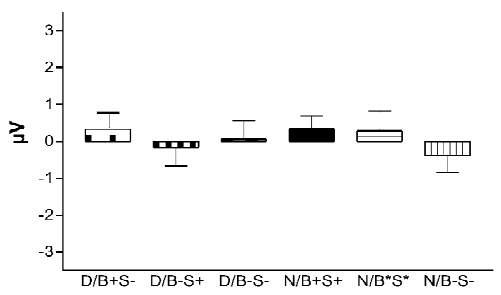

P4

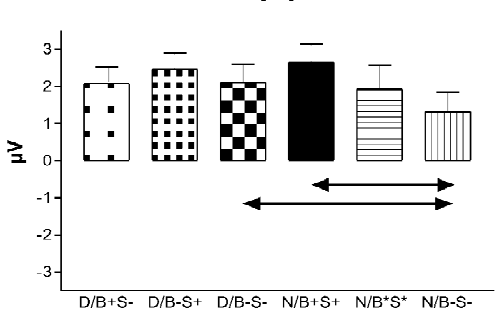

Fig. 3. Mean voltage amplitude values (in $\mu \mathrm{V}$ ) of the N400 time window (320-380 ms after pronoun onset) at the nine most central electrode sites. Solid lines indicate significant planned pair-wise comparison results between conditions (all $P<0.05$ ). The labels at the $x$-axis refer to the conditions as listed in Table 1.

\subsubsection{Non-diminutives versus diminutives}

In Fig. 5 we display double violation conditions $\mathrm{D} / \mathrm{B}-$ $\mathrm{S}-$ and $\mathrm{N} / \mathrm{B}-\mathrm{S}-$ together with baseline $\mathrm{N} / \mathrm{B}+\mathrm{S}+$. Compared to $\mathrm{N} / \mathrm{B}+\mathrm{S}+, \mathrm{N} / \mathrm{B}-\mathrm{S}-$ was more negative, showing an N400 effect at parietal sites. Planned comparisons show significant differences at P3/4 and Pz (Fig. 3 ). In contrast, condition $\mathrm{D} / \mathrm{B}-\mathrm{S}-$ shows only a slight deviation from $\mathrm{N} / \mathrm{B}+\mathrm{S}+$, which was not statistically significant (planned comparison in this time window, NS).

\section{2. $P 600$}

The omnibus ANOVA revealed significant main effects of pronoun types plus interactions of pronoun type with electrodes, as well as with referent types $\times$ electrodes for the P600 time window (Table 3). Specific topographical analyses showed that the P600 effect was neither different between hemispheres, nor between anterior and posterior sites, indicating that the effect is rather widespread.

Fig. 4 shows mean amplitudes per condition per electrode site for nine sites in the P600 latency window. As in Fig. 3, the labels at the $x$-axis relate to the conditions in Table 1. There is a clear ordering of P600 amplitude for the diminutive referent $(\mathrm{D} / \mathrm{B}-\mathrm{S}->\mathrm{D} / \mathrm{B}-\mathrm{S}+>\mathrm{D} / \mathrm{B}+\mathrm{S}-$ ) and non-diminutive referent conditions $(\mathrm{N} / \mathrm{B}-\mathrm{S}->\mathrm{N} /$ $\mathrm{B} * \mathrm{~S} *>\mathrm{N} / \mathrm{B}+\mathrm{S}+)$. Pair-wise planned comparison between conditions were carried out separately for each of the nine most central sites (Fz, Cz, Pz, F3/4, C3/4, P3/4) in order to evaluate the significant ANOVA interactions in more detail.

\subsubsection{Diminutives as referent}

Significant P600 effects were found between conditions $\mathrm{D} / \mathrm{B}+\mathrm{S}-$ and $\mathrm{D} / \mathrm{B}-\mathrm{S}+$ with the latter being more positive at parietal sites $\mathrm{Pz}$ and $\mathrm{P} 4$. The comparison 
F3

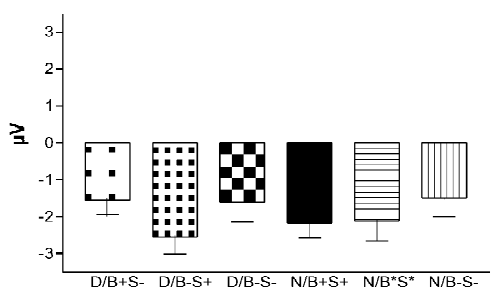

C3

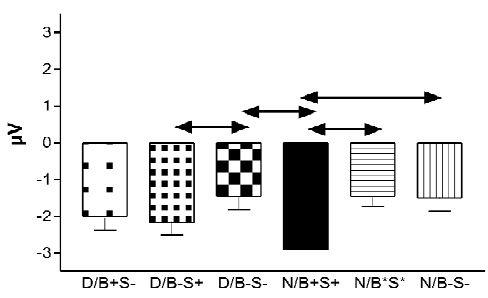

P3

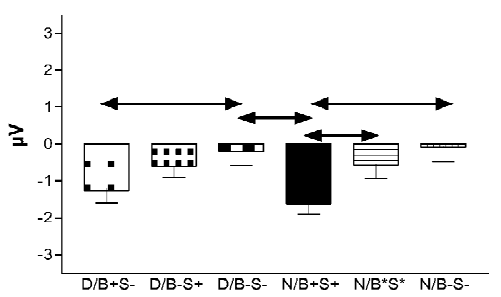

$\mathbf{F z}$

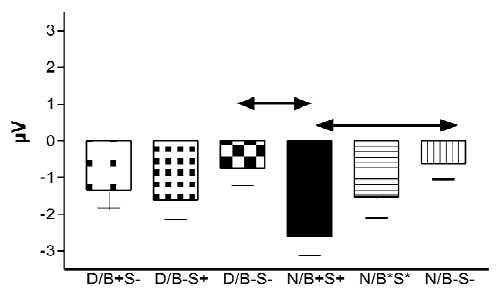

$\mathrm{Cz}$

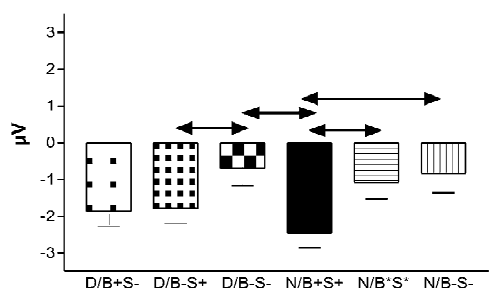

Pz

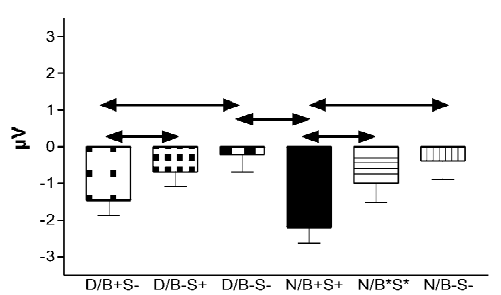

F4

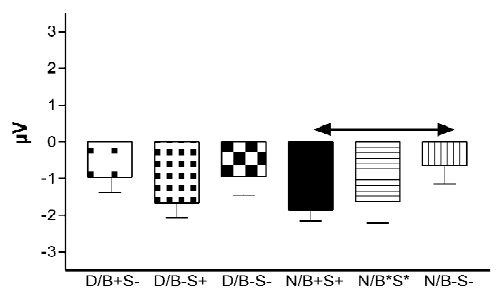

C4

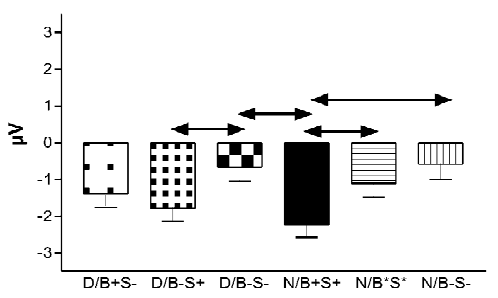

P4

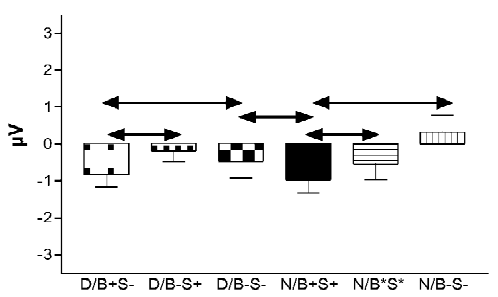

Fig. 4. Mean voltage amplitude values (in $\mu \mathrm{V}$ ) of the P600 time window (400-700 ms after pronoun onset) at the nine most central electrode sites. Solid lines indicate significant planned pair-wise comparison results between conditions (all $P<0.05$ ). The labels at the $x$-axis refer to the conditions as listed in Table 1.

between conditions $\mathrm{D} / \mathrm{B}+\mathrm{S}-$ and $\mathrm{D} / \mathrm{B}-\mathrm{S}-$ was significant at all parietal sites $\mathrm{Pz}$ and $\mathrm{P} 3 / 4$ with the latter being more positive. The contrast between conditions $\mathrm{D} / \mathrm{B}-\mathrm{S}+$ and $\mathrm{D} / \mathrm{B}-\mathrm{S}-$ was significant at all central sites $\mathrm{Cz}$ and $\mathrm{C} 3 / 4$ with the latter being more positive.

\subsubsection{Non-diminutives as referent}

Significant P600 effects were found in the comparison between conditions $\mathrm{N} / \mathrm{B}+\mathrm{S}+$ and $\mathrm{N} / \mathrm{B} * \mathrm{~S} *$, with the latter being more positive at central and parietal sites. The comparison between conditions $\mathrm{N} / \mathrm{B}+\mathrm{S}+$ and $\mathrm{N} / \mathrm{B}-\mathrm{S}-$ was significant with the latter being more positive at frontal sites $\mathrm{Fz}$ and $\mathrm{F} 4$, and at all central and parietal sites. A comparison between conditions $\mathrm{N} / \mathrm{B} * \mathrm{~S} *$ and $\mathrm{N} / \mathrm{B}-\mathrm{S}-$ was not significant.

\subsubsection{Non-diminutives versus diminutives}

In Fig. 5 we display both double violations conditions $\mathrm{D} / \mathrm{B}-\mathrm{S}-$ and $\mathrm{N} / \mathrm{B}-\mathrm{S}-$ together with condition $\mathrm{N} / \mathrm{B}+$
$\mathrm{S}+$. Both double violation conditions were more positive than the baseline $\mathrm{N} / \mathrm{B}+\mathrm{S}+$. Planned pair-wise comparisons (Fig. 4) indicated that they differed significantly from $\mathrm{N} / \mathrm{B}+\mathrm{S}+$ at all central and parietal sites.

Conditions $\mathrm{D} / \mathrm{B}-\mathrm{S}-$ and $\mathrm{N} / \mathrm{B}-\mathrm{S}-$ were not significantly different from each other, indicating that between referent types there is no different processing of pronouns for double violations in this latency window.

\subsubsection{Differences in P600 distribution}

Inspection of the grand averages and the above reported contrasts suggested that the late positivity observed in the different incorrect conditions showed differences in distribution. We therefore computed difference waves subtracting the ERP to the only unequivocally correct condition $(\mathrm{N} / \mathrm{B}+\mathrm{S}+)$ from all other conditions. This resulted in five sets of difference waves reflecting the activity associated with the respective errors. The amplitude of the late positivity was measured in the 400-700-ms time 

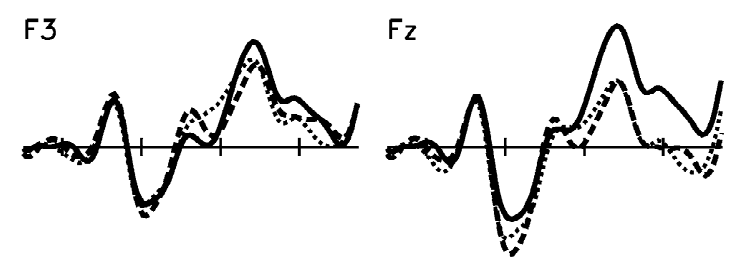

F4
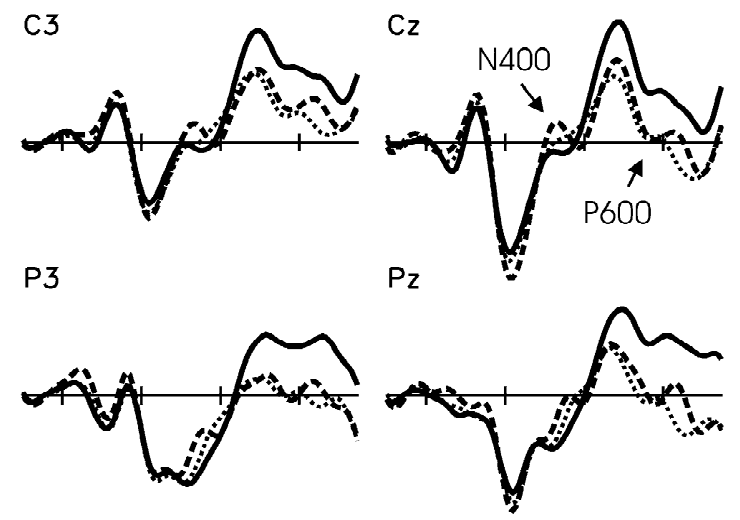

$\mathrm{Cz} \quad \mathrm{C} 4$

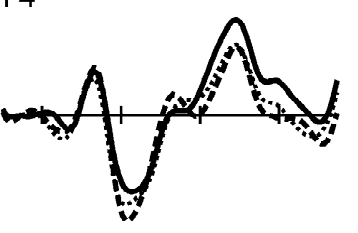

C4

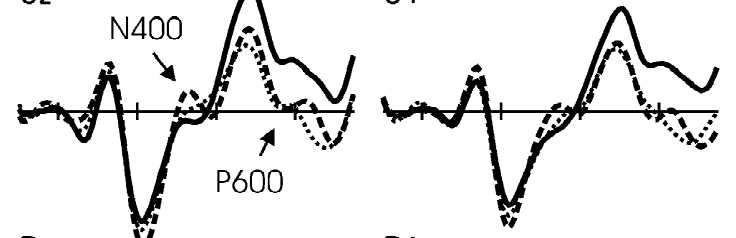

P4
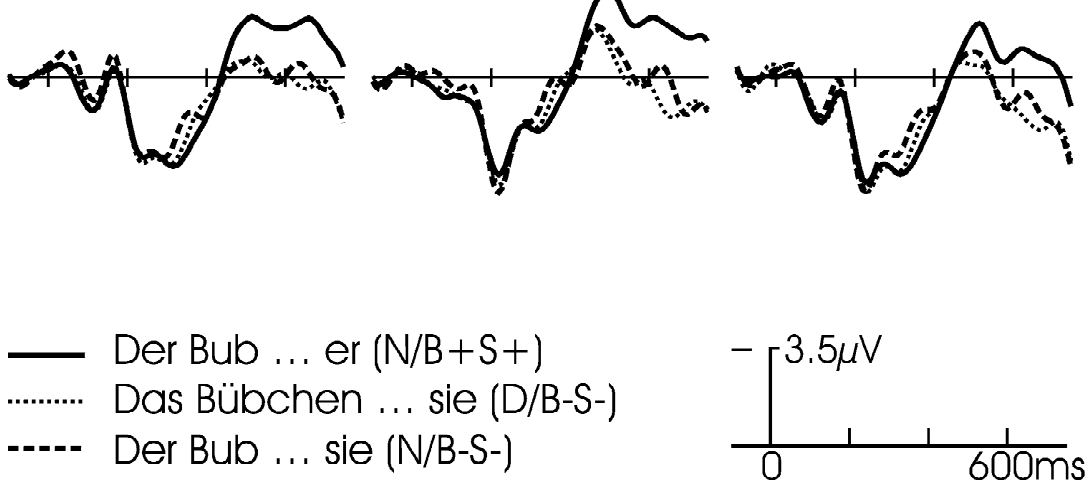

Fig. 5. Grand average $\operatorname{ERPs}(n=30)$ time locked to the onset of the critical pronoun in sentences with the baseline condition $(\mathrm{N} / \mathrm{B}+\mathrm{S}+)$ and non-diminutive double violation $(\mathrm{N} / \mathrm{B}-\mathrm{S}-)$ and diminutive double violation $(\mathrm{D} / \mathrm{B}-\mathrm{S}-)$. Conditions and their labels are illustrated in Table 1.

window at all electrode positions. Fig. 6 shows the five distributions of the positivities (condition minus baseline $\mathrm{N} / \mathrm{B}+\mathrm{S}+$ ), using spline-interpolated isovoltage maps. The topographic maps all show fronto-central and parietal positivities, but they also look slightly different. In order to see whether differences were significant we carried out analyses of variances followed by planned comparison of the data.

After normalizing the data according to the suggestions of McCarthy and Wood [15] they were entered into an ANOVA with factors condition (five levels) and electrodes (28 levels). This ANOVA revealed a significant condition by electrode interaction $\left(F_{108,3132}=2.23, P(\mathrm{HF})<0.0002\right)$ indicating that indeed a differential distribution of the positivity was present. To further follow up on this result, planned pair-wise comparisons between the five different conditions were performed. The Huynh-Feldt corrected $P$-values for the condition by electrode site interaction are shown in Table 4. Statistically the $\mathrm{D} / \mathrm{B}-\mathrm{S}-$ conditions did not differ from the other double violations $(\mathrm{N} / \mathrm{B} * \mathrm{~S} *$ and $\mathrm{N} / \mathrm{B}-\mathrm{S}-$ ). It also did not differ from $\mathrm{D} / \mathrm{B}-\mathrm{S}+$. Condition $\mathrm{D} / \mathrm{B}+\mathrm{S}-$ did not differ from N/B $-\mathrm{S}-$.

The relative anterior-posterior distribution of the P600 is illustrated in Fig. 7. Measurements of the difference waves 'condition minus baseline $\mathrm{N} / \mathrm{B}+\mathrm{S}+$ ' were taken from frontal $(\mathrm{Fz})$ and parietal $(\mathrm{Pz})$ electrodes in the $\mathrm{P} 600$ time window (400-700 ms after pronoun onset). To allow for a visual comparison, the highest value of the difference was set to $100 \%$, and the lower values were adjusted accordingly. As can be seen from the figure, the P600 (positive value of the difference) was high at frontal and parietal sites for all the double violation conditions. It was high at frontal sites, but low at parietal sites for the $\mathrm{D} / \mathrm{B}+\mathrm{S}-$ condition. In contrast, the $\mathrm{P} 600$ positivity was low at frontal sites, but high at parietal sites for the $\mathrm{D} / \mathrm{B}-\mathrm{S}+$ condition.

\section{Discussion}

The aim of the study was to indicate the kind of information that is used by the comprehension system to establish co-reference between a pronoun and its referent. We investigated whether this process of establishing coreference (i.e. bonding and/or integration) relies on conceptual/semantic, on syntactic, or on both types of information. We applied a design that allowed us to disentangle syntactic reanalysis (of syntactic gender agreement) from conceptual/semantic processing (of biological gender agreement) using German non-diminutives and diminutives as referents. The diminutive cases were especially of interest because they have different biological and syntactic gender and allowed for a separate violation of the two gender types. From the ERP literature it is known that 

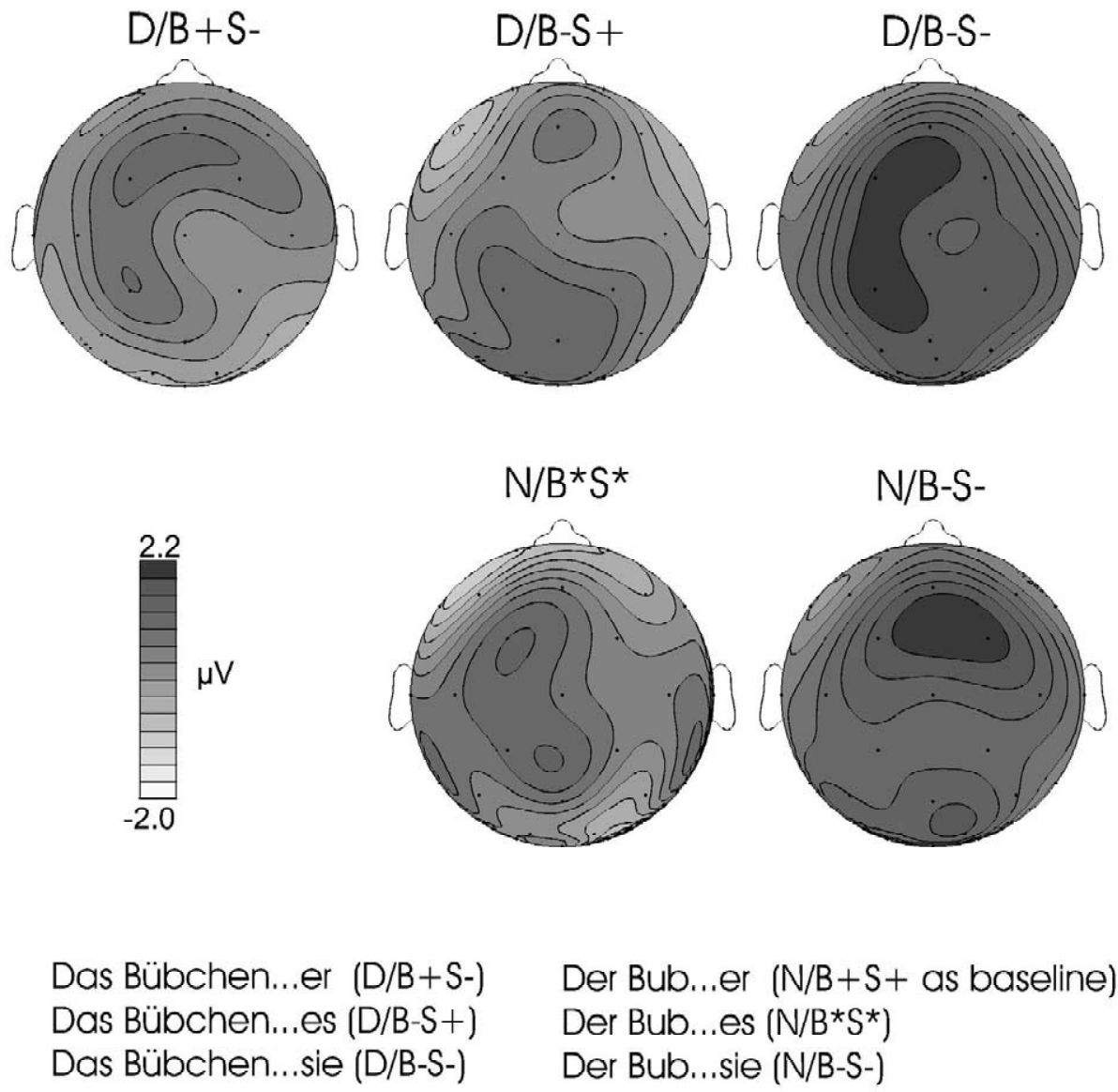

Der Bub...er ( $N / B+S+$ as baseline)
Der Bub...es (N/B* $\left.\mathrm{S}^{*}\right)$
Der Bub... sie (N/B-S-)

Fig. 6. Spline interpolated scalp maps based on the mean amplitude of the difference waves (condition minus baseline N/B $+\mathrm{S}+$ ) in the 400-700-ms time window. To preserve the relative amplitudes of the effects in the different conditions maps were scaled to the maximum and minimum voltage of all data sets.

conceptual/semantic integration manipulates the N400 component. Syntactic processing and sentence reanalysis has been shown to manipulate the P600/SPS. A combined violation was expected to manipulate the N400/P600 complex. By using two different reference types (nondiminutives, diminutives) with three types of third person singular personal pronouns (er, sie, es) six different sentence types were obtained (Table 1) and compared within the N400 and the P600 time window.

\section{Table 4}

Statistical comparison of the mean amplitudes of difference waves (condition minus baseline $\mathrm{N} / \mathrm{S}+\mathrm{B}+$ ) in the 400-700-ms window (P600)

\begin{tabular}{lllll}
\hline & $\mathrm{D} / \mathrm{B}-\mathrm{S}+$ & $\mathrm{D} / \mathrm{B}-\mathrm{S}-$ & $\mathrm{N} / \mathrm{B}^{*} \mathrm{~S}^{*}$ & $\mathrm{~N} / \mathrm{B}-\mathrm{S}-$ \\
\hline $\mathrm{D} / \mathrm{B}+\mathrm{S}-$ & 0.0001 & 0.05 & 0.005 & - \\
$\mathrm{D} / \mathrm{B}-\mathrm{S}+$ & & - & 0.003 & 0.015 \\
$\mathrm{D} / \mathrm{B}-\mathrm{S}-$ & & & & - \\
$\mathrm{N} / \mathrm{B} * \mathrm{~S}^{*}$ & & & & 0.05 \\
$\mathrm{~N} / \mathrm{B}-\mathrm{S}-$ & & & &
\end{tabular}

Prior to the analysis the data have been normalized according to McCarthy and Wood [15]. Shown are the Huynh-Feldt corrected $P$-values for the condition by electrode interaction. Values of $P<0.05$ indicate differences in scalp distribution between difference waves.

\subsection{Co-reference between pronoun and non-diminutive referent}

The ERP signals time-locked to the critical pronoun showed a clear pattern of N400 and P600 effects in the non-diminutive sentence types (Fig. 2). If we take condition $\mathrm{N} / \mathrm{B}+\mathrm{S}+$ as the baseline, a double violation elicited an N400/P600 complex. The N400 effects were present at parietal sites, while the P600 effects were present at parietal and fronto-central sites. The results indicate that a double violation $\mathrm{N} / \mathrm{B}-\mathrm{S}-$ involves both syntactic reanalysis (as reflected in the P600) and semantic processing (as reflected in the N400). For the double violation $\mathrm{N} / \mathrm{B} * \mathrm{~S} *$ it was not clear beforehand whether the comprehension system would treat it as being mainly syntactic or semantic in nature. The ERP results showed P600 effects but no N400 effects (relative to N/B+S+). This indicated that this type of violation, i.e. using the neuter pronoun 'es' for non-diminutives with clear biological gender was treated by the comprehension system as a syntactic rather than a conceptual/semantic violation of gender agreement. 


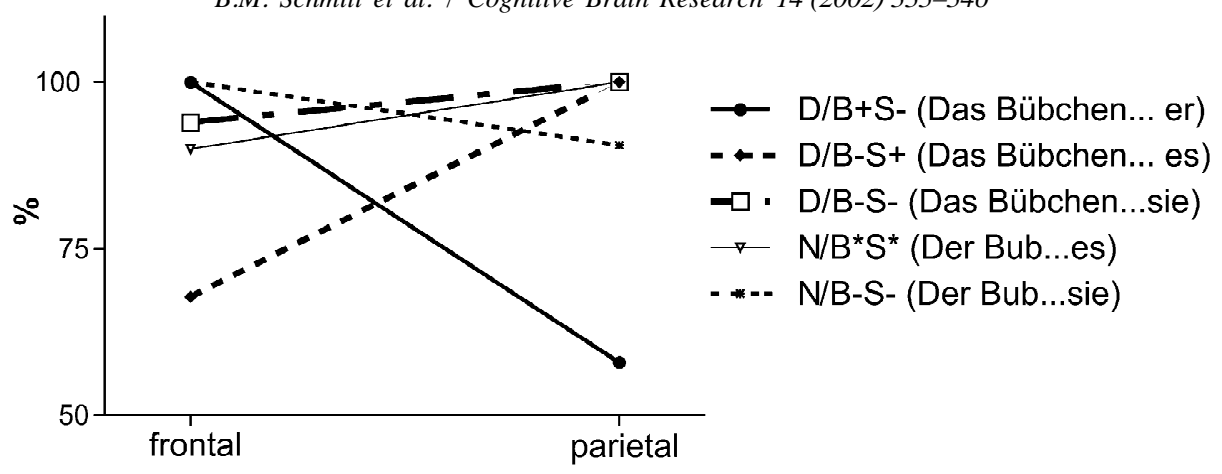

Fig. 7. Anterior-posterior distribution of the P600. To illustrate the relative anterior-posterior distribution of the P600 amplitude measurements were taken at $\mathrm{Fz}$ and $\mathrm{Pz}$ electrodes (time window $400-700 \mathrm{~ms}$, difference waves). The higher value for each condition was set to $100 \%$.

\subsection{Co-reference between pronoun and diminutive}

The ERPs to pronouns in diminutive sentence types did not show any N400 effects, neither compared within diminutive sentence types (Fig. 1), nor compared to the baseline condition N/B $+\mathrm{S}+$ (Fig. 5). This lack of N400 effects in agreement violations indicated that establishing co-reference with a diminutive did not involve semantic integration (i.e. no biological gender information), at least not in a way that semantic processing can easily be violated. As mentioned in the introduction, we know from frequency-of-usage data that a speaker or writer uses a biologically gender marked 'er' or 'sie' instead of the neuter 'es' in $63 \%$ of the cases for co-referring to a diminutive. The neuter 'es' is used in $37 \%$ of the cases. The comprehension system, on the other hand, obviously gets these types of sentences as input and seems to be so flexible that a violation either in biological or syntactic gender is not detected as violation at all in the N400 time window. This seems to hold in the case of single violations, but also in the case of double violation $\mathrm{D} / \mathrm{B}-\mathrm{S}-$. Here, again, the lack of N400 clearly showed that semantic integration is not the major process used to establish co-reference between a pronoun and a diminutive referent.

In contrast to the lack of N400, the ERP to pronouns in diminutive sentence types show clear P600 effects. This P600 pattern is complex, and is most salient at central and parietal electrode sites. In general, if we interpret the P600 as a marker of syntactic reanalysis in a syntactic violation paradigm, the P600 results showed that syntactic reanalysis of the sentence was at hand for the establishment of co-reference between pronouns and diminutives. More specific, at central sites the system detected differences between $\mathrm{D} / \mathrm{B}-\mathrm{S}+$ and $\mathrm{D} / \mathrm{B}-\mathrm{S}-$ (Fig. 1). The difference here in the P600 can be interpreted as indicating the syntactic difference of the two conditions. The system seemed not to differentiate between $\mathrm{D} / \mathrm{B}+\mathrm{S}-$ and $\mathrm{D} / \mathrm{B}-$ $\mathrm{S}+$ conditions at central sites (no significant difference in P600 amplitude). This result might reflect again, as in the N400 time window, but now syntactically, the acceptance of both sentence types in diminutive cases. In contrast to central sites, at parietal sites the syntactic process differen- tiated between $\mathrm{D} / \mathrm{B}+\mathrm{S}-$ and $\mathrm{D} / \mathrm{B}-\mathrm{S}+$, probably reflecting the frequency counts of $63 \%$ acceptable usage of $\mathrm{D} / \mathrm{B}+\mathrm{S}-$ compared to $37 \%$ acceptable usage of $\mathrm{D} / \mathrm{B}-\mathrm{S}+$. In addition, at parietal sites, the system detected a difference between $\mathrm{D} / \mathrm{B}+\mathrm{S}-$ and the double violation $\mathrm{D} / \mathrm{B}-$ $\mathrm{S}-$, with the double violation being more positive, i.e. less syntactically acceptable. At parietal sites, the system did not detect a difference between $\mathrm{D} / \mathrm{B}-\mathrm{S}+$ and the double violation.

\subsection{Comparing non-diminutives and diminutive sentence types}

We thus discovered an interesting dissociation between non-diminutive and diminutive sentences types. Pronouns in non-diminutive referent sentences use both biological gender and syntactic gender to establish co-reference. This can be assumed based on the observed N400/P600 complex pattern evident in the comparison of conditions $\mathrm{N} /$ $\mathrm{B}-\mathrm{S}-$ and $\mathrm{N} / \mathrm{B}+\mathrm{S}+$ (Fig. 5). In contrast, pronouns in diminutive referent sentences do not access biological gender information to establish co-reference, but do access syntactic gender information. This conclusion can be drawn from the comparison of conditions $\mathrm{D} / \mathrm{B}-\mathrm{S}-$ and $\mathrm{N} / \mathrm{B}+\mathrm{S}+$ (Fig. 5). The comparison in the N400 time window was not significant at any electrode site, indicating no N400 effect, and by inference no semantic integration difference between $\mathrm{D} / \mathrm{B}-\mathrm{S}-$ and $\mathrm{N} / \mathrm{B}+\mathrm{S}+$. However, in the P600 time window the two conditions differed significantly, indicating an increased P600 for the double violation as compared to the baseline. The assumption that pronouns in diminutive sentences do not involve access of biological gender information in the N400 time window but rather syntactic gender information was also supported by the comparison between conditions N/B-S - and D/ $\mathrm{B}-\mathrm{S}-$ (Fig. 5). This comparison involved conditions that had the same sort of violation, namely syntactic and biological gender mismatch, and differed in referent type only. The comparison revealed N400 effects, but no P600 effects. The N400 effect was more negative for the condition N/B $-\mathrm{S}-$ than for $\mathrm{D} / \mathrm{B}-\mathrm{S}-$. A possible explanation is that establishing co-reference in non-diminutive- 
referent sentences involves biological gender information (which obviously could be violated), whereas in diminutive-referent sentences biological gender information is not relevant (at least it could not be violated). The absence of a P600 difference between these conditions indicates that similar syntactic reanalysis processes were engaged during the comprehension of these sentences.

\subsection{Topographic distribution of the P600 effects}

We obtained slightly different types of P600 distribution between conditions. In general, we observed a broad fronto-centro-parietal distribution in case of double violations, a fronto-central distribution in case of syntactic violation, and a more parietal distribution in case of semantic violations during syntactic reanalysis. The scalp distribution of all double violations (condition minus baseline $\mathrm{N} / \mathrm{B}+\mathrm{S}+$ in Fig. 6) did not differ from each other statistically. All double violation maps in Fig. 6 show a similar pattern of relatively high fronto-central and parietal positivities. Fig. 7 supports this pattern by showing comparable high values for the positivities of these three double violations at frontal and parietal sites. In contrast, the topographic analysis of the P600 effect for the single violations $\mathrm{D} / \mathrm{B}+\mathrm{S}-$ and $\mathrm{D} / \mathrm{B}-\mathrm{S}+$ showed an interesting interaction across frontal and parietal sites (see especially Fig. 7). The $\mathrm{D} / \mathrm{B}+\mathrm{S}-$ condition elicited the same amount of frontal positivity as the double violations, but it showed a smaller P600 at parietal sites. For the D/B-S+ it is exactly the other way around. The P600 compared to the P600 of double violations is smaller at frontal sites and of equal size at parietal sizes.

If we interpret the $\mathrm{P} 600$ as reflecting reanalysis and more specifically in our case, the reanalysis of co-referencing pronoun and antecedent, the differences in P600 might indicate slightly different types of reanalysis between violation conditions. While admittedly tentative at present, an interpretation of the observed P600 effects could be as follows: The broadly distributed P600 might reflect syntactic analysis that is influenced by both semantic and syntactic gender (dis)agreement information, involving a widespread set of neural generators. In contrast, a P600 of a single syntactic violation condition might reflect reanalysis of syntactic gender (dis)agreement, but no extra semantic processing. Therefore the effect is less widespread, and observed as being strongest at frontal sites. A P600 of a single semantic violation $(\mathrm{D} / \mathrm{B}-\mathrm{S}+)$ might indicate reanalysis of biological gender (dis)agreement during sentence reanalysis. This analysis does not involve syntactic gender (dis)agreement, and therefore we did not observe frontal effects, but effects at parietal sites.

Others have similarly suggested that the P600 might change in topography as a function of the specific reanalysis function required by a certain sentence type. For example, Hagoort and Brown [8] proposed that a more frontally distributed P600/SPS reflects differences in syntactic complexity, whereas more posteriorly distributed P600/SPS might be related to failure and/or revision of a parse. The authors also suggested that the posterior P600/ SPS is a result of a combination of semantic and syntactic violation, due to overlap of N400 and P600 components. Münte et al. [16,17] compared semantic, syntactic and orthographic violations and observed P600/SPS for all three conditions. The positivities differed in their scalp distribution. The semantic violations showed a parietal maximum whereas the orthographic and syntactic violations had wider distributions. The authors suggested that different neural generators contribute to the three types of violation. Such changes in distribution are known from the generic P300 component for which multiple generators have been demonstrated by intracranial recordings that likewise correspond to different cognitive functions [2]. Note that we only speculate here, and that further research will have to show the specific cognitive reasons for our observed P600 topography differences.

In conclusion, the data show that establishing co-reference involves syntactic reanalysis as reflected by the increase of P600 amplitude in violations. This reanalysis can be accompanied by conceptual/semantic integration processes as reflected by the increase of the N400 amplitude in violations in the non-diminutive referent sentences. This N400/P600 showed a classical semantic/ syntactic integration complex, as for example reported by Osterhout and Nicol [21]. However, the semantic integration (reflected by N400) is only present when non-diminutives are referents but not when diminutives are referents. This observed difference between referent types showed that the comprehension system is not working according to fixed syntactic reanalysis rules to establish co-reference but that the process depends on the referent type. Whereas the build-up of co-reference for non-diminutives involves both semantic and syntactic processes, co-reference for diminutives seem to be syntactically driven. One explanation for the difference might be the saliency of biological gender of the referent. Although both types of referents have clear and transparent biological gender assignments, it might be the case that this information is more relevant for nondiminutives as compared to diminutives. Whether and why this is the case has to be shown in the future.

\section{Acknowledgements}

The research reported in this paper was supported by a grant from the Dutch Science Foundation (NWO) to B.M.S., and by grant MU1311/9-1 from the German Science Foundation (DFG) to T.F.M., as a bilateral cooperation project DFG/NWO. We thank Anke Hammer for helping with the collection of the frequency-of-usage data. 


\section{References}

[1] C. Belica, Cosmas: corpus storage, maintainance and access system, http://corpora.ids-mannheim.de/ cosmas/ProtoDocs/Deutsch/ start.html, Institut für deutsche Sprache, Mannheim, Germany, 2000.

[2] J.M. Clarke, E. Halgren, P. Chauvel, Intracranial ERPs in humans during a lateralized visual oddball task: II. Temporal, parietal, and frontal recordings, Clin. Neurophysiol. 110 (1999) 1226-1244.

[3] A.D. Friederici, K. Steinhauer, A. Mecklinger, M. Meyer, Working memory constraints on syntactic ambiguity resolution as revealed by electrical brain responses, Biol. Psychol. 47 (1998) 193-221.

[4] A. Garnham, J. Oakhill, M.F. Ehrlich, M. Carreiras, Representations and processes in the interpretation of pronouns: new evidence from Spanish and French, J. Mem. Lang. 34 (1995) 41-62.

[5] S. Garrot, M. Terros, The contribution of lexical and situational knowledge to resolving discourse roles: bonding and resolution, J. Mem. Lang. 42 (2000) 526-544.

[6] M.A. Gernsbacher, Comprehending conceptual anaphors, Lang. Cogn. Process. 6 (1991) 81-105.

[7] P.C. Gordon, R. Hendrick, The representation and processing of coreference in discourse, Cogn. Sci. 22 (1998) 389-424.

[8] P. Hagoort, C.M. Brown, ERP effects of listening to speech compared to reading: the P600/SPS to syntactic violations in spoken sentences and rapid serial visual presentation, Neuropsychologia 38 (2000) 1531-1549.

[9] P. Hagoort, C. Brown, J. Groothusen, The syntactic positive shift (SPS) as an ERP measure of syntactic processing, Lang. Cogn. Process. 8 (1993) 439-483.

[10] P. Hagoort, C.M. Brown, L. Osterhout, The neurocognition of syntactic processing, in: C. Brown, P. Hagoort (Eds.), The Neurocognition of Language, University Press, Oxford, 1999, pp. 273316.

[11] J.W. King, M. Kutas, Is she an engineer?, Poster presented at the 4th annual meeting of the Cognitive Neuroscience Society, Boston, 1997.

[12] M. Kutas, C.K. Van Petten, Psycholinguistics electrified: eventrelated brain potential investigations, in: M.A. Gernsbacher (Ed.), Handbook of Psycholinguistics, Academic Press, San Diego, CA, 1994, pp. 83-143.

[13] M. Kutas, K.D. Federmeier, S. Coulson, J.W. King, T.F. Muente, Language, in: J.T. Cacioppo, L.G. Tassinary (Eds.), Handbook of Psychophysiology, 2nd Edition, Cambridge University Press, New York, 2000, pp. 576-601.
[14] M. Kutas, J.W. King, The potentials for basic sentence processing: differentiating integrative processes, in: T. Inui, J.L. McClelland (Eds.), Information Integration in Perception and Communication, Attention and Performance, Vol. 16, MIT Press, Cambridge, MA, 1996, pp. 501-546.

[15] G. McCarthy, C.C. Wood, Scalp distributions of event-related potentials: an ambiguity associated with analysis of variance models, Electroencephalogr. Clin. Neurophysiol. 62 (1985) 203208.

[16] T.F. Münte, M. Matzke, S. Johannes, Brain activity associated with syntactic incongruencies in words and pseudowords, J. Cogn. Neurosci. 9 (1998) 318-332.

[17] T.F. Münte, H.J. Heinze, M. Matzke, B.M. Wieringa, S. Johannes, Brain potentials and syntactic violations revisited: no evidence for specificity of the syntactic positive shift, Neuropsychologia 36 (1998) 217-226.

[18] T.F. Münte, T.P. Urbach, E. Düzel, M. Kutas, Event-related brain potentials in the study of human cognition and neuropsychology, in: F. Boller, J. Grafman, G. Rizzolatti (Eds.), Handbook of Neuropsychology, Vol. 1, Elsevier, Amsterdam, 2000.

[19] L. Osterhout, P.J. Holcomb, Event-related brain potentials elicited by syntactic anomaly, J. Mem. Lang. 31 (1992) 785-806.

[20] L. Osterhout, L.A. Mobley, Event-related brain potentials elicited by failure to agree, J. Mem. Lang. 34 (1995) 739-773.

[21] L. Osterhout, J. Nicol, On the distinctiveness, independence, and time course of the brain responses to syntactic and semantic anomalies, Lang. Cogn. Process. 14 (1999) 283-317.

[22] L. Osterhout, M. Bersick, J. McLaughlin, Brain potentials reflect violations of gender stereotypes, Mem. Cognit. 25 (1997) 273-285.

[23] L. Osterhout, P.J. Holcomb, Event related potentials and language comprehension, in: M.D. Rugg, M.G.H. Coles (Eds.), Electrophysiology of Mind: Event-related Brain Potentials and Cognition, Oxford University Press, New York, 1995, pp. 171-215.

[24] M.D. Rugg, M.G.H. Coles, The ERP and cognitive psychology: conceptual issues, in: M.D. Rugg, M.G.H. Coles (Eds.), Electrophysiology of Mind: Event-related Brain Potentials and Cognition, Oxford University Press, New York, 1995, pp. 27-39.

[25] M. St George, M. Kutas, A. Martinez, M.I. Sereno, Semantic integration in reading: engagement of the right hemisphere during discourse processing, Brain 122 (1999) 1317-1325.

[26] J.J. van Berkum, P. Hagoort, C.M. Brown, Semantic integration in sentences and discourse: evidence from the N400, J. Cogn. Neurosci. 11 (1999) 657-671. 